\title{
Tribute
}

\section{PAHEF and PAHO honour renowned Brazilian nutrition expert for Excellence in Leadership in Inter-American Health}

On 27 September 2010, noted nutrition expert Dr Carlos Monteiro of Brazil received the Abraham Horwitz Award for Excellence in Leadership in Inter-American Health.

The award was presented by Dr Benjamin Caballero, Chair of the Pan American Health and Education Foundation (PAHEF), and Dr Mirta Roses Periago, Director of the Pan American Health Organization (PAHO), before an audience of ministers of health, ambassadors, notable US government representatives and executives of Fortune 500 companies.

Dr Monteiro is a seminal figure in the nutrition field, with more than 30 years' experience in research and teaching in the areas of child health, nutrition and epidemiology. His studies on the link between obesity and poverty in developing countries have helped advance understanding of the current nutrition transition in Latin America.

His most recent work explored the decline of stunting (growth impairment resulting from malnutrition) in Brazil. Dr Monteiro and his team found that, over a 33-year period, there was a steady decline in the national prevalence of stunting from $37 \cdot 1 \%$ to $7 \cdot 1 \%$ - evidence that the nation's improving socio-economic status is having a profound impact on children's nutritional intake.
'For me, receiving the Abraham Horwitz Award represents more than the recognition of my own research career', said Dr Monteiro. 'It also recognizes the important role a generation of Latin American researchers has played in advancing the field of nutrition within public health by dedicating their careers to building the field of knowledge'.

Edward L. Kadunc, President of PAHEF, remarked, 'Dr Monteiro has made extraordinary advances not only to nutrition studies in his home country of Brazil, but to the field overall. His studies on the relationship between income and nutritional intake have had a profound influence on understanding how a nation's economic situation influences malnutrition and obesity'.

Created in 1975, the Abraham Horwitz Award for Excellence in Leadership in Inter-American Health honours creative public health leaders whose commitment to public health stimulates excellence among their peers, staff and other public health professionals. Dr Abraham Horwitz served as Director of PAHO from 1958 to 1975 and as President of PAHEF from 1975 to 2000. This year marks the 100th anniversary of his birth.

The award is one of six in the Awards for Excellence in Inter-American Public Health Programme.

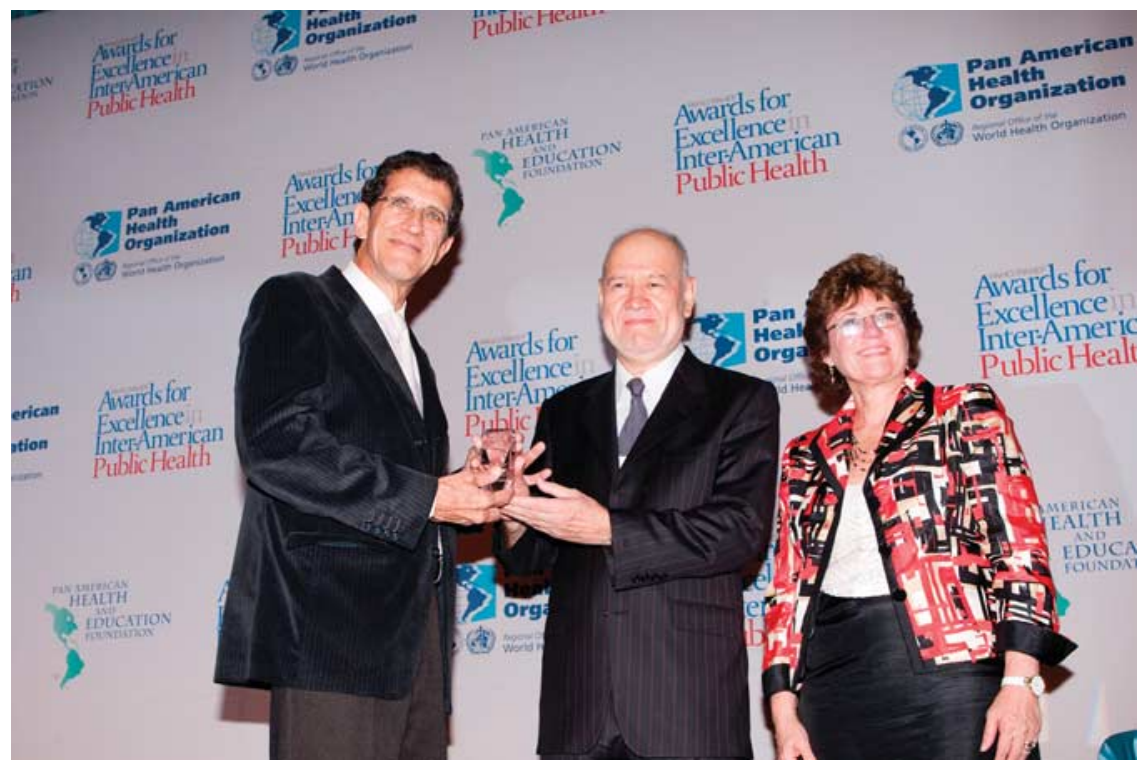

Fig. 1 Dr Benjamin Caballero (centre) and Dr Mirta Roses (right) present Dr Carlos Monteiro (left) with the Abraham Horwitz Award for Excellence in Leadership in Inter-American Health. Photo courtesy of PAHO/WHO 
Founded in 1968, PAHEF is a public 501(c)(3) foundation dedicated to fostering public health programmes in the Americas that address major health concerns. PAHEF improves the lives of people throughout the Americas by working with the public and private sectors as well as major public health research, policy and development groups.

PAHEF frequently collaborates with PAHO, which serves as the WHO Regional Office for the Americas.

The Awards for Excellence in Inter-American Public Health stimulate the growth of the next and rising generation of leaders working together to improve health and health care in the Americas. A jury of distinguished public health professionals reviews nominations and recommends a candidate for each award to the board of directors of the Foundation for final selection. The awards have the unique distinction of recognizing both established and emerging contributors to the field of public health within the Western Hemisphere. Throughout Latin America and the Caribbean, the awards are recognized as a career-defining achievement that brings honour and recognition.

The Awards for Excellence in Inter-American Public Health are co-sponsored by PAHEF and PAHO.

Ashley Gatewood Senior Communications Officer Pan American Health \& Education Foundation (PAHEF) 